\title{
The value of aortic valve replacement in elderly patients: An economic analysis
}

\author{
YingXing Wu, MD, Gary L. Grunkemeier, PhD, and Albert Starr, MD
}

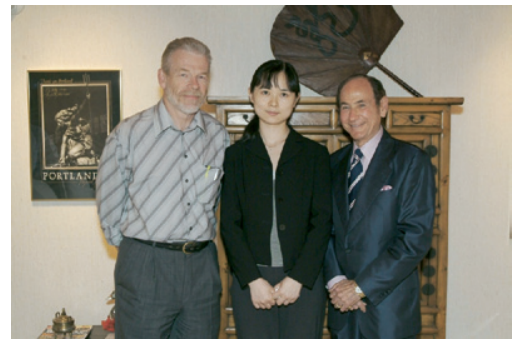

Drs Grunkemeier, Wu, and Starr (left to right)

See related articles on pages 601 and 608.
From Providence Heart and Vascular Institute, Providence Health System, Portland, Ore.

Received for publication April 17, 2006; revisions received July 13, 2006; accepted for publication Aug 7, 2006.

Address for reprints: YingXing Wu, MD, Providence Health System, 9205 SW Barnes, Suite 33, Portland, OR 97225 (E-mail: yingxing.wu@providence.org).

J Thorac Cardiovasc Surg 2007;133:603-7

$0022-5223 / \$ 32.00$

Copyright $@ 2007$ by The American Association for Thoracic Surgery

doi:10.1016/j.jtcvs.2006.08.042
Objective: Economists have designed frameworks to measure the economic value of improvements in health and longevity. Heart valve replacement surgery has significantly prolonged life expectancy and quality of life. For the example of aortic valve replacement, what is its economic value according to this framework?

Methods: From 1961 through 2003, a total of 4617 adult patients underwent aortic valve replacement by one team of cardiac surgeons. These patients were provided with a prospective lifetime follow-up service. As of 2005, observed follow-up was 31,671 patient-years, with a maximum of 41 years. A statistical model was used to generate the future life-years of patients currently alive. The value of life-years proposed by economists was applied to determine the economic value of the additional life given to these patients by aortic valve replacement.

Results: The total life-years after aortic valve replacement were 53,323, with a gross value of $\$ 14.6$ billion. The total expected life-years without surgery were 10,157 , with an estimated value of $\$ 3.0$ billion. Thus the net life-years gained by AVR were 43,166 , worth $\$ 11.6$ billion. Subtracting the $\$ 451$ million total lifetime cost of surgery, the net value of the life-years gained by AVR was $\$ 11.2$ billion. The mean net value decreases according to age at surgery but is still worth $\$ 600,000$ for octogenarians and $\$ 200,000$ for nonagenarians.

Conclusion: According to the economic concept of the value of a statistical life, the return on the investment for aortic valve replacement is enormous for patients of all ages, even very elderly patients.

$\mathrm{T}$ he concept and measurement of gross domestic product, for which the 1971 Nobel Prize was awarded, does not take into consideration improvements to the longevity and health status of the population. Yet from 1900-2000 there was an increase in life expectancy of 28 years for men and 32 years for women. ${ }^{1}$ Improvements in the medical and surgical management of heart disease and preventive measures have undoubtedly played a role in the reduction of age-adjusted death rates from 559 to 232 deaths per 100,000 per year between 1960 and 2003 (Figure 1). ${ }^{2}$ This reduced mortality from heart disease has produced a value of about 1.5 trillion dollars per year, which is not included in the US gross domestic product. $^{3}$

Economist Kevin M. Murphy was recently recognized by the MacArthur Foundation (the "genius award") for his work in assessing the value of a statistical life. In a 2005 article, "The Value of Health and Longevity," Murphy and Topel ${ }^{3}$ developed a framework for assigning an economic value to improvements to health and life expectancy, measuring the value of a single statistical life and the value of each year of life. Such valuations are commonly used by regulatory agencies to determine the cost-effectiveness of environmental regulations. ${ }^{4}$ This method has also been applied to assess the value of increases to the length and quality of life caused by medical advances. 


\section{Abbreviations and Acronyms \\ $\mathrm{AVR}=$ aortic valve replacement}

The clinical benefit of heart valve replacement surgery has been well documented. Our recent study assessed the cost-effectiveness of aortic valve replacement (AVR), which was found to be very cost-effective for patients at all ages, even very elderly patients. ${ }^{5}$ In this investigation we used the same data to determine the value of AVR, especially for elderly patients, with this new econometric methodology.

\section{Materials and Methods}

From 1961 through 2003, a total of 4617 patients older than 20 years underwent AVR on our service at three hospitals in Portland, Ore. The mean age at surgery was 65 years; 502 (10.9\%) were octogenarians and $23(0.5 \%)$ were nonagenarians. Beginning with the first patient, a prospective lifetime follow-up service was implemented. All patients undergoing valve replacement are followed up at annual intervals with a combination of mailed questionnaire and telephone interview. The total follow-up was 31,671 patient-years, with a maximum of 41 years.

The value of AVR was calculated in several steps. All calculations were done at the individual patient level, and the results were presented by grouping age at surgery into 5-year intervals. To facilitate and standardize calculation, all monetary values in the study were adjusted to 2005 dollars with yearly inflation factors obtained from the consumer price index compiled by the US Bureau of Labor Statistics (http://inflationdata.com/Inflation/Inflation_Rate/ HistoricalInflation.aspx).

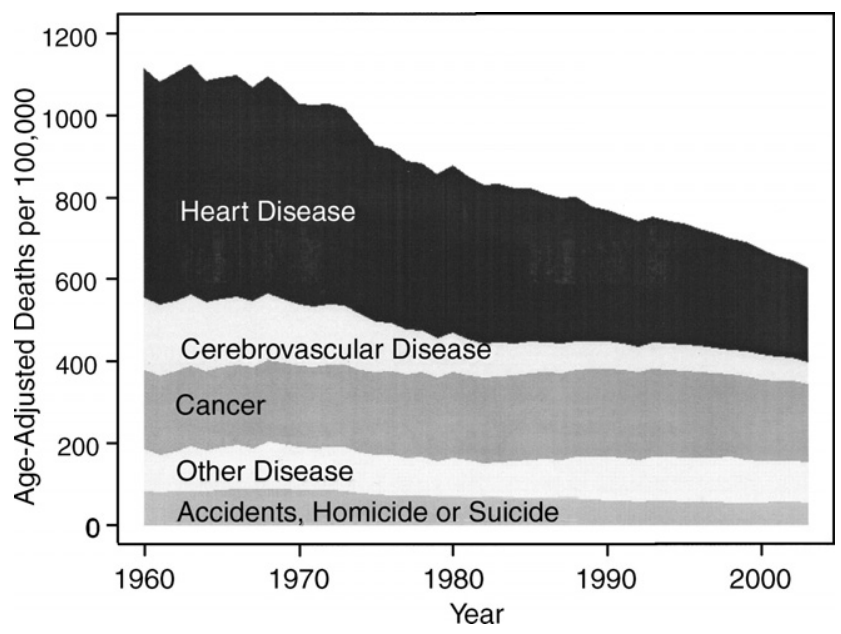

Figure 1. Age-adjusted death rates by major cause of death, United States, 1960-2003. Source data from US National Center for Health Statistics. ${ }^{2}$ Other disease category includes chronic lower respiratory diseases, diabetes mellitus, influenza, pneumonia, chronic liver disease, and cirrhosis.
Step 1: Determine the value of a life-year (economic framework). Economists Murphy and Topel ${ }^{3}$ developed an economic framework for assigning a dollar amount to improvements to health and life expectancy, measuring the value of a single statistical life and the value of each year of life. This work indicates that the relationship between the value of a life-year and age is characterized by an inverted U-shaped curve, which peaks around age 50. These published estimates were converted from 2000 dollars to 2005 dollars with the inflation factors (Figure 2).

Step 2: Determine survival after AVR. Survival after AVR was determined from the observed data from our follow-up system and completion of the currently censored lifetimes with a Gompertz regression model derived from the observed patient data, as previously described. ${ }^{5}$ Gompertz regression has been widely used to model survival time in survival analysis, especially for elderly persons. ${ }^{6}$ The simulation was repeated 1000 times, and the mean was used in the final calculation.

Step 3: Determine survival of patients with aortic valve disease not operated on (natural history). Mean survival of patients with severe aortic valve disease not operated on was approximately 2.2 years, as determined by a previously described literature review. ${ }^{5}$

Step 4: Cumulative years of survival after AVR by patient age. The value of a life-year proposed by Murphy and Topel $^{3}$ is dependent on an individual's age, so for each year a patient lived after AVR a dollar value was assigned according to age in that year. For example, a patient who had AVR at age 69.4 years and lived 5.0 years would contribute 0.6 year to age 69 years, 1 year each to ages $70,71,72$, and 73 years, and 0.4 year to age 74 years. This calculation was repeated for every patient, and the results were added to obtain the total life-years at different ages after AVR.

Step 5: Cumulative years of survival of patients with severe aortic valve disease not operated on by patient age. The average survival for unoperated aortic valve disease was 2.2 life-years. The patient in the previous example thus would have

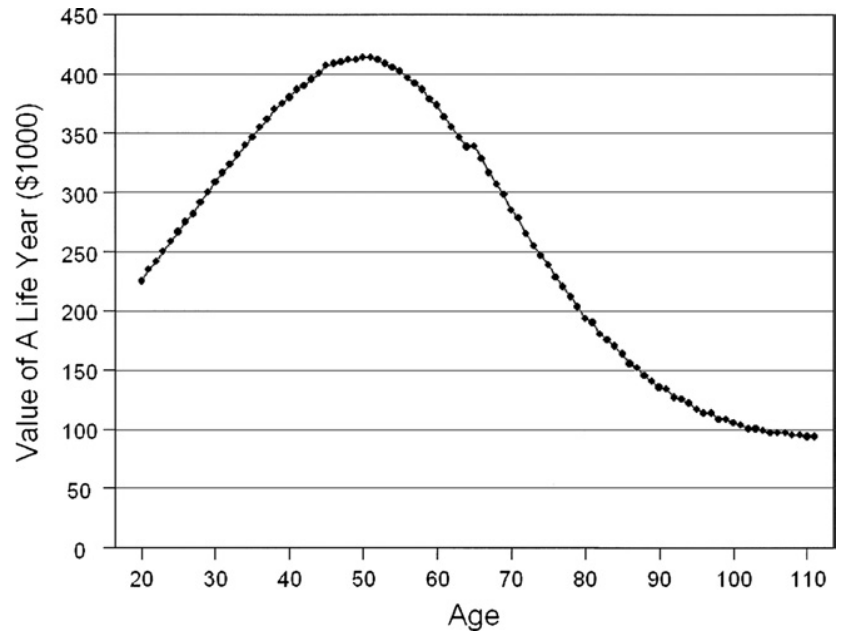

Figure 2. Value of life-year by age in $\mathbf{2 0 0 5}$ dollars, as derived from Murphy and Topel. ${ }^{3}$ 


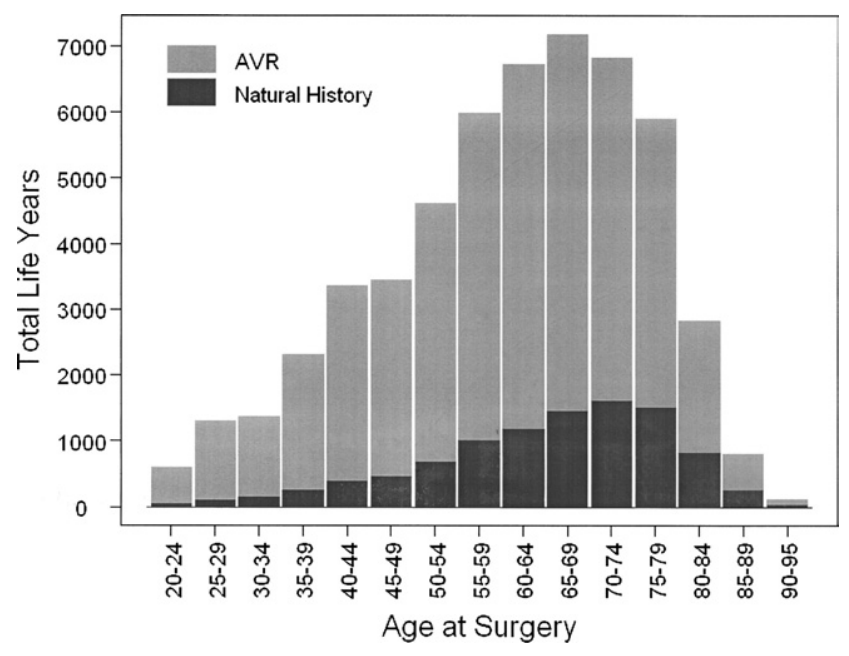

Figure 3. Total life-years after aortic valve replacement (light gray bar) and natural history (dark gray bar) by age at surgery. $A V R$, aortic valve replacement.

lived 2.2 years without operation. He would contribute 0.6 year to age 69 years, 1 year to age 70 years, and 0.6 year to age 71 years. The same calculation was repeated for every patient, and the results were summed to obtain the total life-years at different ages without operation.

Step 6: Net life-years gained from AVR. For each patient, life-years gained by AVR were calculated as the life-years after AVR (step 4) minus the life-years with unoperated heart valve disease (step 5). Note that not all individual patients benefited from AVR. Those who lived for a shorter time than expected, for example patients with a surgically related death, contributed a negative amount to the total gain from surgery. Total life-years gained by AVR was obtained by summing the life-years gained by each patient.

Step 7: Economic value of life-years gained by AVR. For each patient the value of life-years gained was calculated by summing the value of a life-year at each year of age defined by the economic framework (step 1, Figure 2). The value of life-years gained by each patient was summed to get the total value of life-years gained after AVR. For the example in step 4, the value of life years after AVR would be $(0.6 \times \$ 299,000)+\$ 285,000+$ $\$ 279,000+\$ 265,000+\$ 255,000+0.4 \times \$ 247,000=\$ 1.36$ million, and the value of the natural history would be $(0.6 \times$ $\$ 299,000)+\$ 285,000+(0.6 \times \$ 279,000)=\$ 0.63$ million. The value gained by AVR would be $\$ 0.73$ million for the patient.

Step 8: Net value of AVR. The lifetime costs of AVR (cost of the original surgery, of ongoing maintenance, and of treating valve-related complications) were calculated as described previously. ${ }^{5}$ The net value of AVR by age at surgery was obtained by subtracting the lifetime cost from the value of life-years gained (step 7).

\section{Results}

Survivals (mean $\pm \mathrm{SE}$ ) after AVR were $50 \% \pm 0.9 \%$, $20 \% \pm 1.0 \%, 6.8 \% \pm 0.8 \%$, and $3.9 \% \pm 0.8 \%$ at 10,20 ,

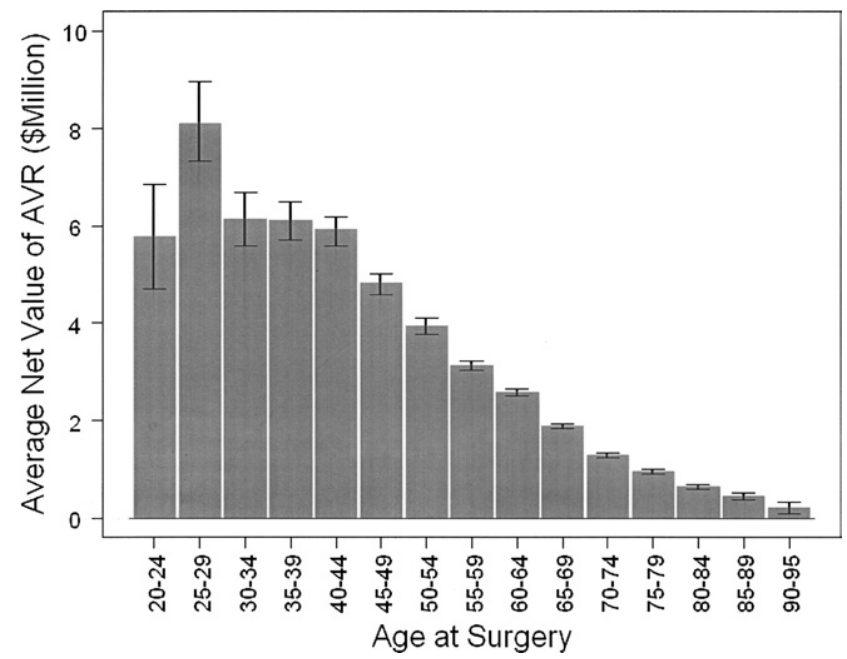

Figure 4. Average net value gained after aortic valve replacement by age at surgery (gray bar). Error bars indicate $95 \%$ range from 1000 times simulation. $A V R$, aortic valve replacement.

30 , and 40 years, respectively. For the 2382 patients who died, a total of 17,525 follow-up years were observed. For the 2235 patients with censored data, a total of 14,146 follow-up years were documented, and an additional 21,652 years were imputed from the regression model.

The total life-years after AVR were 53,323 (total area of the light gray bars, including the part covered by the dark gray bars, in Figure 3). The total expected life-years without surgery were 10,157 (area of the dark gray bars superimposed on the light gray bars in Figure 3). The difference between the light and dark gray bars (the visible light gray area), 43,166 years, represents the total life-years gained by AVR. The total value of the life-years after AVR was $\$ 14.6$ billion; the total value of the expected life-years without surgery was $\$ 3.0$ billion. Thus the value of life-years gained by AVR was $\$ 11.6$ billion. After deduction of the lifetime cost of $\$ 451$ million, the net value of AVR was $\$ 11.2$ billion. Figure 4 shows the average net value of AVR by age at surgery. The mean net value decreases according to age at surgery but is still worth $\$ 600,000$ for octogenarians and $\$ 200,000$ for nonagenarians.

\section{Discussion}

We previously showed AVR to be very cost-effective ${ }^{5}$ according to generally accepted thresholds, ${ }^{7,8}$ even for very elderly patients. These thresholds, however, are arbitrary. Economists have developed a framework for assigning an economic value to a life-year. In this study we evaluated the value of AVR with this new concept.

The enormous value of AVR ( $\$ 11.6$ billion) compared with its cost ( $\$ 451$ million) is noteworthy and surprising. The method used, however, was based on established economic 
analysis. Although the exact value used is a source of debate among economists, there is an agreement that the true value is a degree of magnitude greater than the traditional valuations that are based only on future lifetime earnings. Several methods have been devised to estimate this value.

One method uses consumer market analysis. We all purchase items that reduce our risk of dying (fire alarm, automobile airbags, bicycle helmet, etc). Suppose there is a risk of 1 in 10,000 of death from a certain cause. In a group of 10,000 people, 1 such death would be expected. Suppose there is an item that eliminates that risk, and the market value of that item is $\$ 500$. If all 10,000 people in that group purchased the item, 1 "statistical death" would be prevented at a total cost of $\$ 5$ million. That figure could then be taken as the value of a "statistical life."

Another method uses labor market analysis. Suppose that two jobs, A and B, are similar except that B includes a hazardous duty component that adds a 1 in 1000 risk of fatality. Because of that higher risk, job B pays $\$ 5000$ more. By multiplication, 1 whole fatality would be "worth" 1000 times $\$ 5000$, or $\$ 5$ million. This is the method used by Murphy and Topel, ${ }^{3}$ whose article on this subject was used for our cost estimates. There are other sources addressing this subject and its limitations, ${ }^{9-14}$ including some easy-toread articles or books on the subject by Murphy and Topel ${ }^{9}$ and David Cutler. ${ }^{13,14}$

Murphy and Topel ${ }^{3}$ estimated the value of a statistical life at $\$ 6.3$ million in 2000 dollars between ages 25 and 55.3 That value was based on research results from the US Environmental Protection Agency, which gave a range of $\$ 5.5$ to $\$ 7.6$ million in 2000 dollars. ${ }^{4}$ Other analyses and meta-analyses have come up with different values, but all are within the same order of magnitude (the following are in millions of 2005 dollars): $\$ 1.8$ to $\$ 3.0,{ }^{15} \$ 1.1$ to $\$ 3.6,{ }^{16} \$ 2.6$ to $\$ 4.7,{ }^{17} \$ 2.9$ to $\$ 15.3,{ }^{18} \$ 2.9$ to $\$ 11.2,{ }^{19} \$ 4.5$ to $\$ 10.5,{ }^{20}$ $\$ 7.7,{ }^{21} \$ 3.6$ to $\$ 10.9,{ }^{22}$ and $\$ 7.2 .{ }^{11}$ Because our study is the first venture into this new area, we only provided the point estimates based on Murphy and Topel's work. ${ }^{3}$ The next step of investigation would be doing sensitivity analyseklttltts and adding confidence intervals to the estimates.

The value of AVR arrived at by this study considered only the extended life-years of our patients relative to their expected lifetimes if not operated on. These extra years also have a higher quality than exists with the natural history of the disease. ${ }^{5}$ A monetary value could also be attached to this improvement in quality of life. There is no published evidence, however, that persons with physical limitations or chronic illnesses are willing to pay less to increase their longevity than are persons without these limitations. ${ }^{23,24}$ We deducted the lifetime cost of AVR but did not add the costs of caring for patients with severe unoperated disease. Had this aspect also been considered, the value attached to AVR would have been slightly higher.
The candidates for AVR are getting older and sicker. Elderly patients undergoing AVR have achieved satisfactory results in terms of both long-term survival and quality of life. The length of the study crossed 4 decades, during which there were changes in patient profile, surgical technique, and health care policy. We have been operating on octogenarians since the 1980s and on nonagenarians since the 1990s. Physicians may still be hesitant to recommend elderly patients for surgical therapy merely on the basis of clinical outcome, because cardiac valve surgery in elderly patients is associated with higher resource use in light of their limited life expectancy. Even considering lifetime costs and changing patient profiles, however, the value of AVR is still tremendous for all time periods (the graphs for different time periods were similar, results not shown), even for elderly patients, according to this economic concept.

This report provides an insight into the enormous economic value of effective medical therapy, with AVR as an example. It is to be hoped that this methodology will be applied to other therapies in the future as a guide to the most effective medical care.

\section{References}

1. Arias E. United States Life Tables, 2001. National Vital Statistics Reports. Natl Vital Stat Rep. 2004;52(14):1-38.

2. National Center for Health Statistics (US). Vital statistics of the United States: annual statistical abstract of the United States: 2006. Section 2 , vital statistics.

3. Murphy KM, Topel RH. The value of health and longevity. NBER working papers series No. 11405. Cambridge (MA): National Bureau of Economic Research; 2005.

4. Dockins C, Maguire K, Simon N, Sullivan M. Value of statistical life analysis and environmental policy: a white paper. Washington, DC: Environmental Protection Agency (US), National Center for Environmental Economics; 2004.

5. Wu Y, Jin R, Gao G, Grunkemeier GL, Starr A. Cost-effectiveness of aortic heart valve replacement in the elderly. J Thorac Cardiovasc Surg. 2007;133:608-13.

6. Wu Y, Grunkemeier GL. Statistical analysis of the results of heart valve replacement. Expert Rev Cardiovasc Ther. 2003;1:559-68.

7. Kaplan RM, Bush JW. Health-related quality of life measurement for evaluation research and policy analysis. Health Psychol. 1982;1:61-80.

8. Laupacis A, Feeny D, Detsky AS, Tugwell PX. How attractive does a new technology have to be to warrant adoption and utilization? Tentative guidelines for using clinical and economic evaluations. CMAJ 1992;146:473-81.

9. Murphy KM, Topel R. Medical research: What's it worth? Milken Institute Review. 2000; First quarter:23-30.

10. Brannon II. What is a life worth? Regulation. 2004;27:60-3.

11. Ackerman F, Heinzerling L. If it exists, it's getting bigger: revising the value of a statistical life. Working paper No. 01-06. Boston: Global Development and Environment Institute; 2003.

12. Murphy KM, Topel RH. Measuring the gains from medical research: an economic approach. London: University of Chicago Press; 2003. p. $1-240$.

13. Cutler DM, McClellan M. Is technological change in medicine worth it? Health Aff (Millwood). 2001;20:11-29.

14. Cutler DM. Your money or your life: strong medicine for America's health care system. Oxford, UK: Oxford University Press; 2004. p. 176.

15. Mrozek J, Taylor L. What determines the value of life? A metaanalysis. J Policy Analysis Manage. 2002;21:253-82.

16. Krupnick A, Cropper M, Alberini A, Simon N, O’Brien B, Goeree R Age, health and the willingness to pay for mortality risk reductions: a 
contingent valuation survey of Ontario residents. J Risk Uncertainty. 2002;24:161-75.

17. Miller TR. The plausible range for the value of life-red herrings among the mackerel. J Forensic Econ. 1990;3:17-40.

18. Fisher A, Chestnut L, Violette D. The value of reducing risks of death: a note on new evidence. J Policy Anal Manage. 1989;8:88-100.

19. Leeth JD, Ruser J. Compensating wage differentials for fatal and nonfatal injury risk by gender and race. J Risk Uncertainty. 2003;27: 257-77.

20. Viscusi WK. The value of risks to life and health. J Econ Lit. 1993; 31:1912-46

21. Viscusi WK, Aldy JE. The value of a statistical life: a critical review of market estimates throughout the world. NBER working papers series No. W9487. Cambridge (MA): National Bureau of Economic Research; 2003. Available from: URL: http://ssrn.com/abstract= 379270

22. Viscusi WK. The value of life in legal contexts: survey and critique. Am Law Econ Rev. 2000;2:195-210.

23. Environmental Protection Agency Science Advisory Board (US), Environmental Economics Advisory Committee Panel for Review of the White Paper.Valuing the benefits of fatal cancer risk reduction. Washington: The Agency; 2000.

24. Alberini A, Cropper M, Krupnick A, Simon NB. Does the Value of a Statistical Life Vary with Age and Health Status? Evidence from the United States and Canada. Journal of Environmental Economics and Management. 2004;48:769-92.

\section{ON THE MOVE?}

\section{Send us your new address at least six weeks ahead}

Don't miss a single issue of the journal! To ensure prompt service when you change your address, please photocopy and complete the form below.

Please send your change of address notification at least six weeks before your move to ensure continued service. We regret we cannot guarantee replacement of issues missed due to late notification.

\section{JOURNAL TITLE:}

Fill in the title of the journal here.

\section{OLD ADDRESS:}

Affix the address label from a recent issue of the journal here.

\section{NEW ADDRESS:}

Clearly print your new address here.

Name

Address

City/State/ZIP

\section{COPY AND MAIL THIS FORM TO:}

Elsevier Inc.

Subscription Customer Service

6277 Sea Harbor Dr

Orlando, FL 32887
OR FAX TO:

407-363-9661

OR E-mail:

elspcs@elsevier.com
OR PHONE:

800-654-2452

Outside the U.S., call

407-345-4000 